\title{
ENSINO DE LÍNGUAS ESTRANGEIRAS E PRÁTICA MÉDICA NO PROJETO LET'S GO: UMA PERSPECTIVA HUMANIZADA
}

\author{
LA ENSEÑANZA DE LENGUAS EXTRANJERAS Y PRÁCTICA MÉDICA EN EL \\ PROYECTO LET'S GO: UNA PERSPECTIVA HUMANIZADA
}

\author{
TEACHING FOREIGN LANGUAGES AND MEDICAL PRACTICE \\ LET'S GO PROJECT: A HUMANIZED PERSPECTIVE
}

\author{
Nildicéia Aparecida ROCHA ${ }^{1}$ \\ Silke Anna Thereza WEBER ${ }^{2}$ \\ Larissa Pierri CARVALHO ${ }^{3}$ \\ Eduardo FONSECA ${ }^{4}$
}

RESUMO: A sociedade atual cada vez mais se caracteriza pelo trabalho cognitivo e, no contexto de globalização, a língua estrangeira (LE) é a primeira das barreiras para a inserção do indivíduo a nível nacional e internacional. Um facilitador importante do aprendizado de uma segunda língua é a introdução precoce na aprendizagem da LE (BROWN, 2001), aproveitando assim a curiosidade natural das crianças para introduzilas na aprendizagem de uma outra língua além de sua língua materna. Para isso, o professor precisa trabalhar sua habilidade de transmitir conhecimentos de modo mais compreensível, promovendo uma capacidade essencial para o futuro médico, uma postura humanizada. Neste sentido, o presente trabalho focaliza as experiências que os médicos em sua formação acadêmica tem realizando ao atuarem como promotores da aprendizagem de língua inglesa no cotidiano de alunos do $5^{\circ}$ ano da escola de Ensino Fundamental, junto ao Projeto de Extensão Let`s Go, que pretende despertar neles o interesse pela LE e também integrar os estudantes da Faculdade de Medicina de Botucatu com crianças de um meio social diferente para aprimorarem, assim, suas habilidades interpessoais e de comunicação. Metodologicamente, sob a orientação e supervisão de professores da área de ensino e aprendizagem de LE e da Medicina, foi desenvolvida uma apostila pelos alunos da faculdade de Medicina para promoverem aulas de inglês, uma vez por semana, para 90 alunos de três classes do $5^{\circ}$ ano do Ensino Fundamental de duas escolas municipais. Para avaliação do curso pelos alunos, foi elaborado um questionário aplicado no início e no fim do ano letivo. Observa-se, de modo geral, pela análise do corpus (questionários) que o Projeto Let's Go tem atingido os objetivos: promover e sensibilizar para o aprendizado de língua inglesa, além de proporcionar a interação dos alunos da Faculdade de Medicina de Botucatu com a comunidade, numa perspectiva humanizada.

1 Professora Assistente Doutor junto ao Departamento de Letras Modernas (área de Língua Espanhola/LE) da Faculdade de Ciências e Letras - Campus de Araraquara - UNESP. E-mail: nildirocha@fclar.unesp.br

${ }^{2}$ Professora Adjunto da Universidade Estadual Paulista Júlio de Mesquita Filho.Professora Programa de Pós-graduação do Instituto Nacional de Ensino, Pós-Graduação e Extensão. E-mail: silke@ @mb.unesp.br

${ }^{3}$ Bolsista Projeto Let's Go e aluna da Faculdade de Medicina, Campus de Botucatu/UNESP. E-mail: larissapcarvalho9@gmail.com

${ }^{4}$ Bolsista Projeto Let's Go e aluno da Faculdade de Medicina, Campus de Botucatu/UNESP 
PALAVRAS-CHAVE: Ensino de línguas estrangeiras. Prática médica. Abordagem humanizada.

RESUMEN: La sociedad actual cada vez más se caracteriza por el trabajo cognitivo y, en el contexto de globalización, la lengua extranjera (LE) es una primera de las barreras para la inserción del individuo a nivel nacional e internacional. Un facilitador importante del aprendizaje de una segunda lengua es la introducción precoz en la enseñanza de una LE (BROWN, 2001), aprovechando así la curiosidad natural de los niños para introducirles en el aprendizaje de una otra lengua además de su lengua materna. Para eso, el profesor necesita trabajar su habilidad de transmitir conocimientos de modo más comprensible, promoviendo una capacidad esencial para el futuro médico, desde una perspectiva humanizada. En este sentido, este trabajo se centra en experiencias que médicos en su formación académica están realizando al actuar como promotores del aprendizaje de lengua inglesa en el cotidiano de alumnos del $5^{\circ}$ año de una escuela de Enseñanza Fundamental en el Proyecto de Extensión Let s Go, que pretende despertar en los alumnos el interés por la LE y además integrar los estudiantes de la Facultad de Medicina de Botucatu con niños de un medio social diferente para, así, mejorar sus habilidades interpersonales y de comunicación. Metodológicamente, bajo la orientación y supervisión de profesores del área de enseñanza y aprendizaje de LE y de Medicina, fue desarrollada una apostilla por los estudiantes de la facultad de Medicina para promover las clases de inglés, una vez por semana, para 90 alumnos de tres salas del $5^{\circ}$ año de la Enseñanza Fundamental de dos escuelas municipales. Para la evaluación del curso de inglés por los alumnos, fue elaborado un cuestionario y aplicado al inicio y al final del año lectivo. Se observa, de modo general, por el análisis del corpus (cuestionarios) que el Proyecto Let's Go ha logrado llevar a cabo los objetivos propuestos: promover y sensibilizar para el aprendizaje de lengua inglesa, y proporcionar la interacción de los estudiantes de Medicina de Botucatu con la comunidad, según la perspectiva humanizada.

PALABRAS CLAVE: Enseñanza de lenguas extranjeras. Práctica médica. Abordaje humanizado.

ABSTRACT: Society today is increasingly characterized by cognitive work and, in the context of globalization, a foreign language (FL) is the first barrier that must be overcome to the to the insertion of an individual at a national and international level. An important facilitator to the learning of a second language is the early introduction of a FL (Brown, 2001), making use of child's natural curiosity to introduce them in to the study of another language. For that, the teacher needs to work his skill to transmit knowledge in a more comprehensible way, improving an essential skill for a future doctor, assuming a more humanized posture. In that way, this study focus on the experiences that medical students undergo as promoters of the learning of English for students of the 5th year of the Elementary School, through the extension project Let's Go. This project aims to awaken in children the interest for a FL as well as to interface the students of the Faculty of Medicine of Botucatu with children from a different social context, developing their interpersonal and communication skills. As method, a brochure was produced by the medical students under the supervision and orientation of languages and medicine professors. The brochure is used as material to English classes once a week to 90 children of three classes of the 5th year of the Elementary 
School of two public schools. In order to evaluate the course, a questionnaire was elaborated and applied at the beginning and at the end of the school year. It is observed that, in general terms, through the analysis of the questionnaires, that the project Let's Go is achieving its objectives: to promote and encourage the learning of English, as well as to interact medical students of the Faculty of Medicine of Botucatu with the community in a humanized perspective.

KEYWORDS: Teaching foreign languages. Medical practice. Humanized approach.

\section{Introdução}

A sociedade atual cada vez mais se caracteriza pelo trabalho cognitivo em detrimento do esforço físico, seja para o convívio social, exercer uma profissão e até mesmo exercer a própria cidadania (FINI, 2008). Devido a isso, aumenta cada vez mais uma antiga desigualdade em nosso país, a desigualdade de conhecimento. $\mathrm{Na}$ contemporaneidade, considerado o contexto de globalização, tanto a exclusão social por falta de recursos financeiros ou de conhecimento são indesejáveis, sendo a língua estrangeira (LE) a primeira das barreiras a ser quebrada, de modo a evitar o isolamento de um indivíduo de uma sociedade em constante avanço e em processo de internacionalização dos povos e países.

Segundo Brown (2001), a eficácia com que a linguagem se desenvolve é maior na infância do que na fase adulta, sendo, portanto, a introdução precoce da LE um fator de grande importância na facilitação do aprendizado da segunda língua. Além disso, o uso e ensino de uma LE nos primeiros anos escolares auxiliam no desenvolvimento pleno das potencialidades individuais de cada criança, exercitando concomitantemente o trabalho coletivo. Tais atividades estimulam a independência e autonomia pessoal, deixando-a mais segura quanto às suas capacidades e limites e favorecendo o seu completo desenvolvimento biopsicossocial.

Outros motivos para o ensino da LE em crianças é a curiosidade natural que elas possuem, um forte motivador que é vital para a aquisição de novos conhecimentos. Sendo assim, as aulas de LE para crianças devem se basear em atividades lúdicas e de interação entre os colegas. Com isso em mente, no ensino da LE, inicialmente, a perfeição não deve ser o objetivo a ser alcançado, e sim o estímulo do aluno a se interessar e se sensibilizar em aprender e usar a nova língua.

Sobre o aprendizado, Oliveira (1992, p. 33) destaca que: “A aprendizagem desperta processos internos de desenvolvimento que somente podem ocorrer quando o 
indivíduo interage com outras pessoas", evidenciando a importância das atividades lúdicas no ensino da LE para crianças.

Frente a essa conjuntura, o ensino da LE “[...] não é só um exercício intelectual de aprendizagem de formas estruturais [...], é sim, uma experiência de vida, pois amplia as possibilidades de se agir discursivamente no mundo". (BRASIL, MEC, 1998, p. 38).

Somando-se essas questões e voltando-se o olhar para o professor, este, quando ensina, não só reforça seus conhecimentos adquiridos em sua formação docente como promove um processo de ensino e aprendizagem que favorece uma aprendizagem de LE aos alunos de modo mais compreensível. Transferindo essa atividade para a prática médica, o ensinar para crianças possibilita aos estudantes de Medicina por em prática uma das tarefas mais complexas da profissão médica: transformar o saber técnico em um conhecimento que seja mais acessível ao paciente, favorecendo uma relação médico-paciente menos autoritária e desigual e permitindo que o paciente se sinta mais seguro e melhor informado sobre sua condição, sendo estes pontos chave de uma Medicina mais humanizada.

Ainda sobre o professor, o contato com indivíduos de um meio social diferente do seu expande seus horizontes quanto à situação social da população. Este contexto de ensino e aprendizagem articulado à prática médica promove uma expansão de horizontes para o médico a ser formado de forma vital, para que ele consiga se colocar no papel do paciente e assim compreender suas angústias e inseguranças, possibilitando também uma mais adequada práxis médica.

Deste modo, no Projeto de Extensão Let's Go, um subprojeto do Centro de Línguas da Unesp de Botucatu, composto por alunos da Faculdade de Medicina de Botucatu (FMB), propusemo-nos a oferecer aulas de inglês para crianças do $5^{\circ}$ ano do Ensino Fundamental de duas Escolas Públicas de Botucatu, sob a perspectiva teóricometodológica aqui apresentada. Deste modo, passamos a apresentar nossa proposta de promoção do ensino de LE e de humanização na formação acadêmica dos alunos do referido Curso de Medicina.

\section{Projeto Let's go: uma proposta diferenciada}

Tendo em vista o contexto apresentado, apresentamos os objetivos do Projeto de Extensão Let's Go: 
- Introduzir de maneira lúdica a língua inglesa no cotidiano de alunos do $5^{\circ}$ ano, de modo a despertar neles o interesse pela LE, estimular a busca individual pelo conhecimento, tornando-os independentes de um modelo no qual o aluno é passivo em seu aprendizado, e atinja um maior aproveitamento do ensino da língua nos anos subsequentes, dada a importância da LE na sociedade globalizada que vivemos.

- Integrar os alunos da Faculdade de Medicina de Botucatu com crianças de um meio social diferente, para que desenvolvam suas habilidades de compreensão e entendimento, aprimorem suas habilidades interpessoais e de comunicação e também para que se sintam mais seguros quanto aos seus conhecimentos e como repassá-los, seja de língua inglesa ou de outras áreas, de modo a ter uma formação médica mais voltada para a assistência integral e humanizada do doente e não apenas ao tratamento de doenças.

Considerando os objetivos expostos, metodologicamente as aulas são ministradas por alunos de graduação do curso de Medicina da Faculdade de Medicina de Botucatu (FMB/Unesp) para 90 alunos de três classes do $5^{\circ}$ ano do Ensino Fundamental, sendo duas classes da Escola Municipal de Ensino Fundamental "Angelino de Oliveira" e uma da Escola Municipal "Luiz Carlos Aranha Pacheco". As aulas são ministradas semanalmente, ocorrendo todas as sextas-feiras letivas, com duração de 50 minutos, das 12:30 às 13:20, para que não coincida com a grade horária dos alunos da FMB e da escola e que os alunos do ensino fundamental pudessem ter uma atividade na sequência de suas aulas da grade curricular.

Como material didático, os próprios professores (alunos da FMB) confeccionaram uma apostila com o conteúdo a ser utilizado no curso, sob a orientação e supervisão da professora coordenadora do Projeto. Assim, foi distribuída uma apostila para cada um dos 90 alunos das três salas envolvidas no projeto e cada professor também recebeu uma apostila individual. Este material segue a abordagem comunicativa e cultural, de acordo com o descrito a seguir.

Como metodologia de ensino utilizada no processo de ensino e aprendizagem de inglês, as aulas incorporaram diversos métodos e técnicas de ensino eficazes no ensino de uma LE para crianças, seguindo as orientações de ênfase comunicativo-cultural. São elas:

- Model, Action, Talk (Modelo, ação e fala) - faz uso de exercícios de repetição rápidos e intensivos, estimulando o aluno a adquirir a maior quantidade de vocabulário no menor tempo possível (repetir constantemente o vocabulário, e 
permitir que as crianças interajam entre si. Exemplo: apontar coisas em inglês e pedir que as crianças traduzam rapidamente e vice-versa).

- Total Physical Response (Resposta física total) - baseia-se na concepção de que movimentos físicos ajudam na retenção do conhecimento (as crianças guardam o conhecimento de maneira lúdica e usando o corpo. Exemplo: cantando a música do alfabeto, levantando e apontando qual cor de roupa estão utilizando).

- Function Approach (Função de aprendizagem) - além de traduzir o vocabulário a ser utilizado, utilizá-lo de maneira aplicada e mostrando a origem do termo, facilitando a compreensão do conteúdo (Exemplo: exemplificar quando cada vocabulário pode ser aplicado em sua realidade - o botão Stop do DVD chama Stop porque Stop significa "PARAR").

- Comunicative Method (Método comunicativo) - este método faz uso de um aprendizado centrado no aluno, deixando o professor de ser um fornecedor puro de conhecimentos e o aluno passivo, apenas recebendo as informações. Nesse método, o professor torna-se mais um orientador do aluno. Para que esta abordagem funcione, o professor deve ter um bom vínculo com os alunos, mostrando-se atento às dúvidas que surgem, estimulando a participação e aceitando críticas e sugestões que eventualmente surjam.

Para avaliação do curso pelos alunos das escolas municipais, os quais serviram de objeto de análise neste estudo, foram elaborados questionários aplicados antes do início da primeira aula do ano letivo e posteriormente no fim do ano letivo. Por meio da análise destes questionários, corpus desse estudo, pode-se observar o conhecimento inicial e o final dos alunos ao longo de seu aprendizado de língua inglesa no que se refere a: conhecimentos prévios, apreciação sobre a língua inglesa, valorização do inglês e aprendizagem da LE durante o Projeto.

O Projeto tem sido desenvolvido desde 2012 e se tem observado, ao longo destes anos e de modo reflexivo, que há muito interesse por parte dos alunos da escola pública e dos alunos do curso de Medicina em participar ativamente no Projeto, pois tem promovido a aprendizagem e o gosto pela língua inglesa e tem despertado uma perspectiva mais humanizada na formação do futuro médico.

\section{Resultados alcançados}

Os resultados obtidos por meio dos questionários aplicados estão representados nos gráficos a seguir, tendo em vista que foi aplicado um questionário no início do 
curso, antes da primeira aula, e outro no encerramento do ano letivo. Das 90 crianças participantes do projeto, apenas 48 estavam presentes no dia da aplicação do questionário final, sendo as ausentes excluídas da representação.

No questionário inicial, as duas primeiras perguntas não possuíam equivalentes no questionário final e serviam para delinear o perfil do público-alvo do projeto quanto ao conhecimento de língua inglesa, sendo elas:

1. Você já teve algum contato com inglês?

2. Você já estudou ou está estudando inglês em alguma escolinha?

Contabilizando as respostas obtidas, para a primeira pergunta houve um total de 23 “sim" e 25 "não". Em relação à segunda pergunta, a maior parte dos participantes respondeu negativamente (36 respostas de 48), estando tais dados representados na Figura 1.

Figura 1: A coluna da esquerda mostra as respostas obtidas na pergunta 1, enquanto a coluna da direita mostra as respostas obtidas na pergunta 2

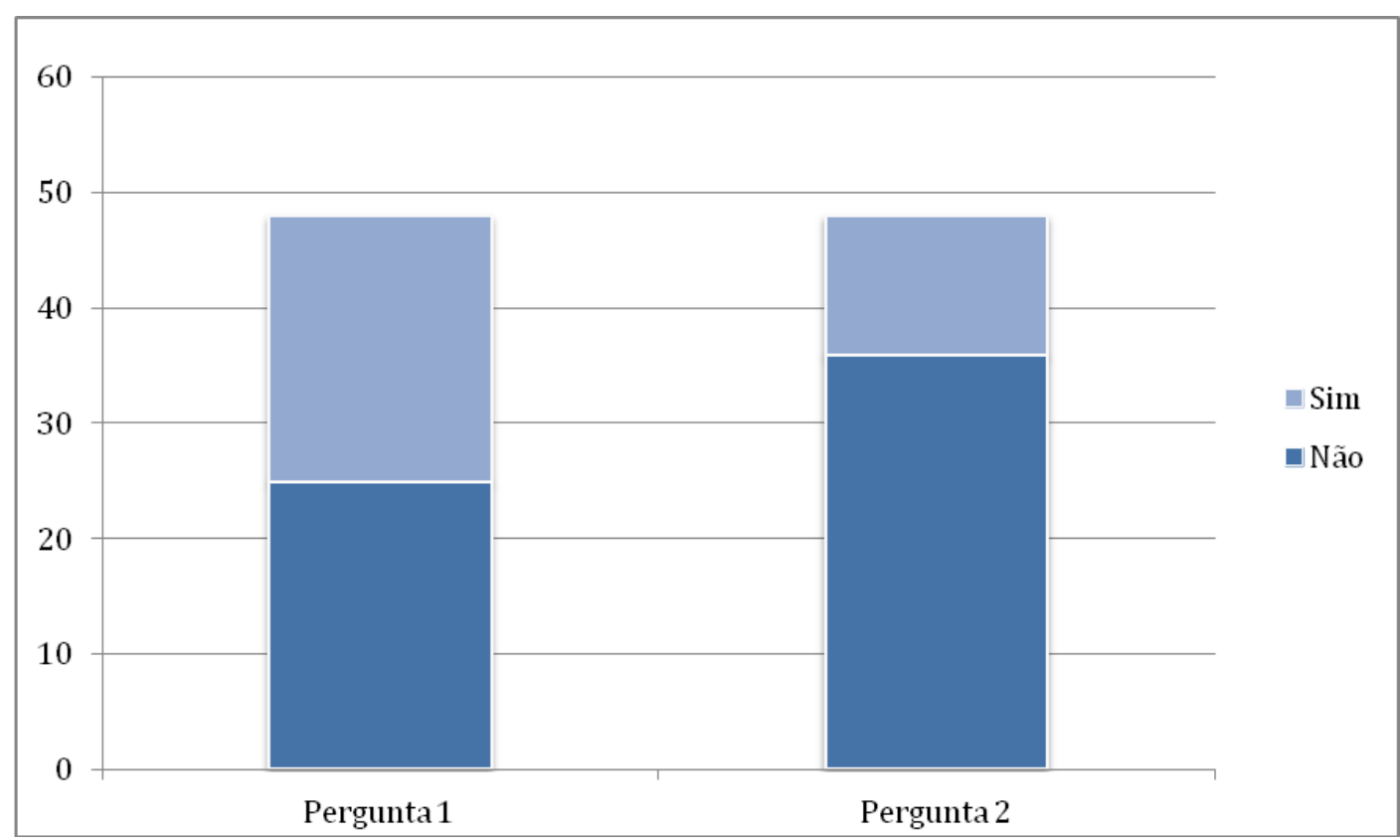

Fonte: elaboração própria com base nos dados obtidos na pesquisa

Pode-se verificar assim, que a maioria das crianças da escola observada não possuía conhecimentos prévios de inglês, e uma porcentagem mais equilibrada dos alunos havia tido algum contato com a língua inglesa. Este diferencial, ou seja, ter 
algum contato com inglês maior do que tê-lo estudado sistematicamente, pode ser compreendido pela quantidade de termos e expressões em inglês que se encontram no cotidiano das pessoas no Brasil, tendo em vista pelo menos dois aspectos: inicialmente a tradição de mais de 30 anos do ensino majoritariamente de inglês em território nacional, em detrimento de outras línguas estrangeiras, e, por outro lado, as crianças em geral terem contato e certa familiaridade com aparelhos eletrônicos, os quais em sua maioria apresentam termos em inglês. Ademais, no Brasil o ensino de língua estrangeira na escola formal inicia-se a partir do $5^{\circ}$ ano da escola fundamental, portanto, essas crianças estariam em um primeiro contato com o inglês.

Quanto às perguntas presentes em ambos questionários, e, portanto, passíveis de análise comparativa dos resultados, foi perguntado aos alunos:

1. Você acha que inglês é fácil de aprender?

2. Você gosta de aprender inglês?

3. Você acha que com esse curso você estará/está mais preparado para acompanhar inglês na próxima escola?

4. Você acha que inglês vai ser importante para sua vida futura?

As respostas, representadas na Figura 2, mostraram que os valores positivos para a pergunta 1 aumentaram de 22 para 24 ao final do ano e as respostas indefinidas, caracterizadas na opção "não sei” aumentaram de 14 para 17. Já as respostas negativas diminuíram notavelmente, passando de 12 para 2. Sobre o segundo questionamento, os valores se mantiveram relativamente estáveis, com aumento de 37 para 38 para a resposta afirmativa e queda de 4 para 3 respostas negativas. A quantidade de respostas indefinidas se manteve inalterada. A terceira pergunta apresentou um resultado diferente, pois foi a única na qual as respostas negativas tiveram um aumento, de 3 para 5 , e que se deu em detrimento das respostas indefinidas, que diminuíram de 12 para 5. Apesar disso, as respostas afirmativas aumentaram de 33 para 35. Em relação à quarta pergunta, esta apresentou resultados dentro do esperado, porque as respostas afirmativas aumentaram de 41 para 44, as indefinidas diminuíram de 6 para 3 e a negativa se manteve em 1. 
Figura 2: Gráfico mostra a quantidade de respostas "sim", "não sei" e "não" para cada uma das perguntas presentes no questionário inicial e final

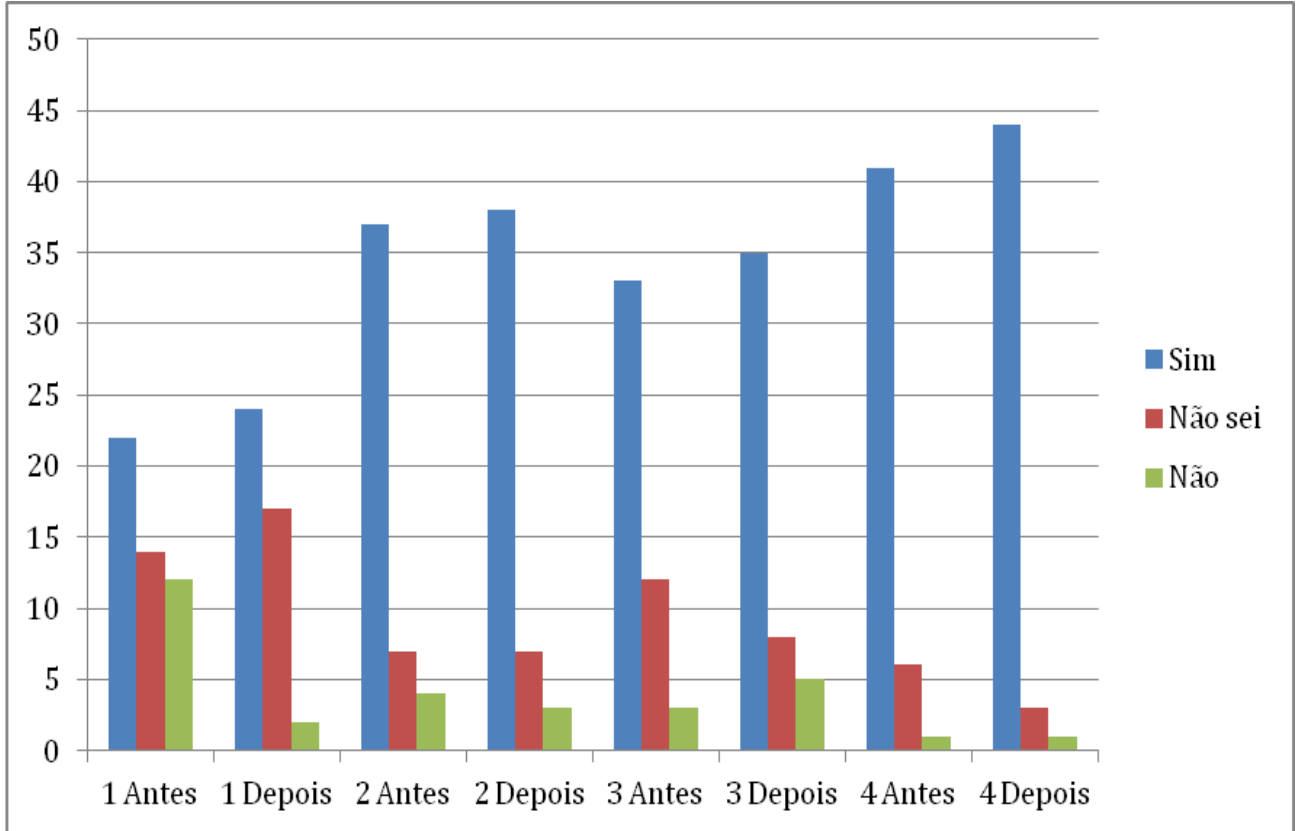

Fonte: Elaboração própria com base nos dados obtidos na pesquisa

Com relação às perguntas anteriormente apresentadas pode-se inferir:

- Primeira pergunta - facilidade de aprender inglês: houve um significativo decréscimo sobre considerar difícil aprender inglês, pois no final do curso apenas 2 dos 48 alunos ainda consideravam o aspecto de dificuldade em aprender esta língua; pode-se observar, assim, a efetividade das aulas oferecidas aos grupos de alunos, pela diminuição em considerá-la de difícil aprendizado; entretanto, é importante notar a negativa em ser uma disciplina fácil de aprender, pois houve um grande diferença: inicialmente 12 negaram, mas depois apenas dois consideraram não ser fácil aprender inglês, talvez porque tenham entendido a complexidade de se estudar uma língua estrangeira, que vai além de repetir e memorizar estruturas linguísticas.

Segunda pergunta - gosto em aprender inglês: neste quesito, os alunos mostraram pouca alternância, mas também se registrou aumento no gosto pelo inglês, assim, confirmamos pela segunda vez a relevância deste projeto, ressaltamos, como mencionado anteriormente, que todos os dias estamos expostos à língua inglesa constantemente, por isso também este projeto tem pertinência.

Terceira pergunta - estar mais preparado para estudar inglês: nesta pergunta há um importante aumento de alunos que consideraram estar melhores preparados para 
estudar inglês no futuro, reforçando a proposta e as estratégias de ensino de inglês no presente Projeto, assim como confirmando as considerações de Brown (2001), sobre iniciar-se o ensino mais precoce de uma LE.

- Quarta pergunta - importância do inglês para os alunos: também é percebido que há uma valorização significativa em considerar a língua inglesa como um elemento importante na vida futura dos alunos, pode-se perceber globalmente que esta valorização é mundial, pois a língua inglesa é a primeira língua de importância e em número de falantes no mundo, deste modo, os alunos podem se considerar mais preparados para a atualidade.

Além das perguntas já descritas, outras duas foram feitas com o objetivo de avaliar o rendimento e aceitação do curso pelos alunos, sendo elas:

1. Como foi seu contato com inglês?

2. Você considera que aprendeu bastante coisa?

As respostas obtidas estão representadas na Figura 3. Ambas as perguntas apresentaram grande diferença entre as respostas positivas, negativas e indefinidas. $\mathrm{Na}$ primeira pergunta, foi obtido um resultado de 42 respostas positivas "bom", 2 indefinidas "mais ou menos" e 4 negativas “ruim". Já a pergunta 2 teve um resultado de 35 respostas positivas, 14 indefinidas e apenas 1 ruim.

Figura 3: Gráficos mostram a distribuição de respostas obtidas nas perguntas relativas ao aproveitamento e aceitação do curso 


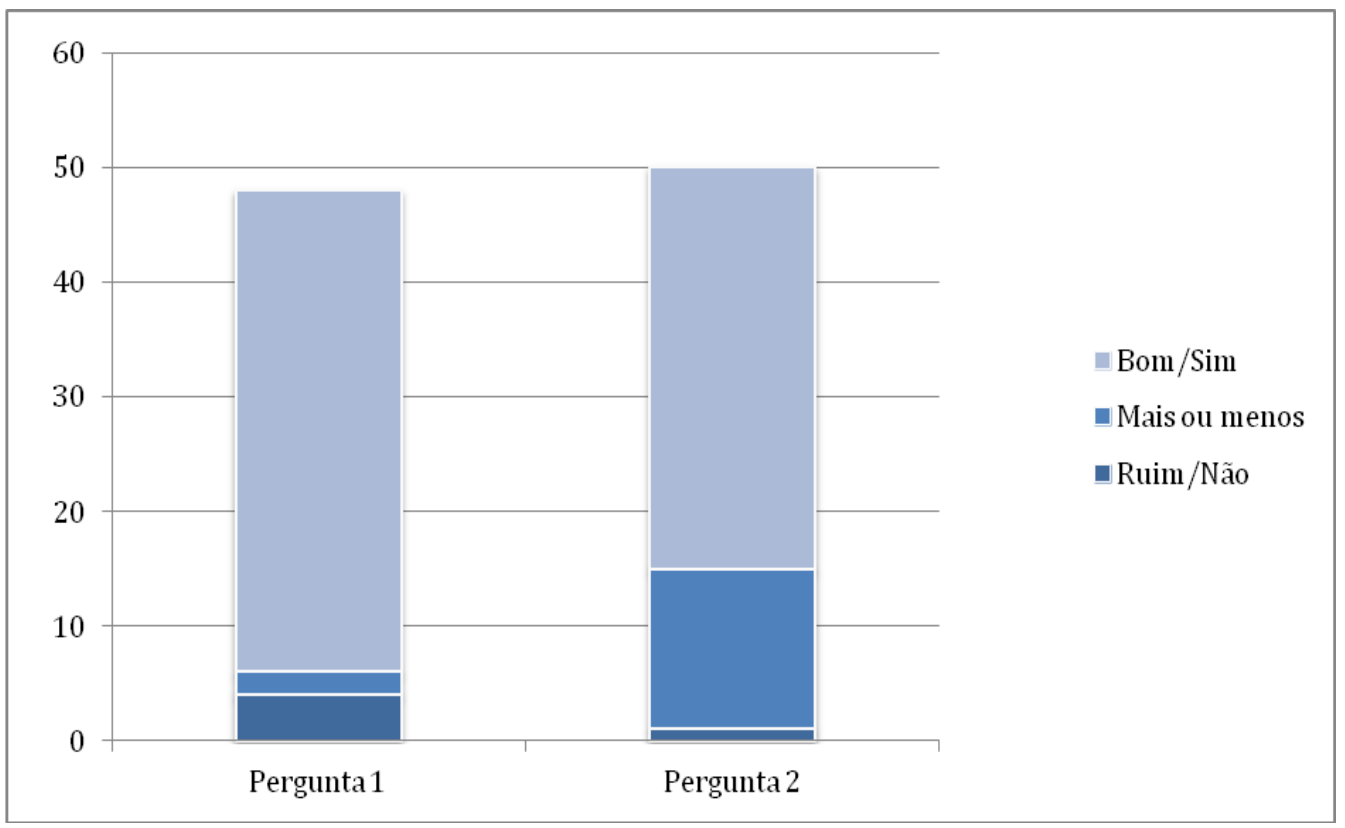

Fonte: elaboração própria com base nos dados obtidos na pesquisa

Nestas duas últimas perguntas, mais uma vez, houve uma mudança importante na valorização da aprendizagem de língua inglesa, considerando que foi um “contato bom" com a língua nas aulas do Projeto Let's Go e também que aprenderam "bastante". Assim sendo, mesmo considerando este estudo em fase inicial, pode-se confirmar a relevância e pertinência deste Projeto e a sua continuidade, além de talvez poder servir de inspiração a novas experiências humanizadas na formação do futuro médico no Brasil.

\section{Discussão dos dados}

Por meio da avaliação dos resultados obtidos nos questionários aplicados, percebe-se que o projeto atingiu os objetivos estipulados. Como previsto inicialmente, o contato com o inglês é algo inerente ao dia a dia, fazendo parte da vida de mais da metade dos alunos, mesmo sendo o público-alvo de uma condição social mais vulnerável. Ou seja, mesmo já tendo contato prévio com a língua, para $75 \%$ dos alunos o primeiro contato formal com o inglês, com aulas e professores, ocorreu durante as aulas do Projeto Let's Go, o que reitera a importância e o poder de impacto deste Projeto de Extensão na formação global desse aluno.

A partir das respostas do questionário inicial, nota-se que os alunos não possuíam preconceito com relação ao ensino da LE, revelando que a maioria não tinha 
medo de inglês, inclusive acreditando, portanto, que teria facilidades em aprendê-lo. Tal expectativa dos alunos foi alcançada, sendo que após o curso a maioria continuou considerando que inglês era fácil de aprender, e outras 5 crianças, que responderam que inglês era difícil no início do curso, mudaram de posição, considerando a LE fácil de aprender no questionário final. Do total de 48 alunos, $77 \%$ das crianças declararam gostar de aprender inglês antes mesmo da primeira aula, valor que subiu para $79 \%$ no questionário final, indicando que as aulas conseguiram sim alimentar e estimular o interesse dos alunos pela nova língua. Sobre seu preparo para acompanhar o inglês na futura escola, $68 \%$ deles acreditavam que o curso os prepararia melhor, resultado que não só foi atingido como ultrapassado, aumentando para $73 \%$ ao final do ano letivo.

Quando perguntados sobre a importância do inglês em suas vidas, as respostas positivas cresceram de $85 \%$ a $91 \%$ ao final do curso, mostrando que mesmo antes das aulas os alunos já entendiam a importância da LE, em especial o inglês - uma das línguas mundialmente mais faladas e de maior importância na produção científica, econômica e de acesso a diferentes culturas -, e que, com o conhecimento adquirido, mais crianças enxergaram a importância da segunda língua em sua vida.

A avaliação final do curso pelos alunos foi de extrema importância, pois $87 \%$ deles consideraram seu contato com o inglês bom, e 69\% consideraram que aprenderam bastante. Tal dado revela que os alunos não só gostam do Projeto Let's Go, como este acrescenta em sua formação cultural, fato que também estimula os coordenadores e professores a investir em um projeto de tão grande impacto para a sociedade.

Desse modo, apesar de as aulas serem curtas, apenas uma vez por semana (50 minutos) e o projeto ainda carecer de investimento institucional, foi possível transmitir a importância da língua inglesa para os alunos e mostrar que o aprendizado da LE não é difícil, como muitas vezes esperado por eles, principalmente por meio de estratégias didáticas que incorporam as atividades lúdicas e o estímulo à busca individual pelo conhecimento como método de ensino.

\section{Considerações Finais}

Com base no exposto, conclui-se que o Projeto Let's Go atingiu seus objetivos de introdução dos alunos participantes no ensino e aprendizado da língua inglesa e 
também quanto a interação dos alunos da Faculdade de Medicina de Botucatu com a comunidade.

Agradecimentos: Agradecemos à Prof. Dra. Mariângela Spotti Lopes Fujita, PróReitora de Extensão da UNESP e ao Prof. Dr. José Carlos Peraçoli, Vice-diretor da FMB, por todo apoio e incentivo dado ao projeto, possibilitando que esse fosse realizado e expandido com sucesso. Agradecemos também a todos os alunos da Faculdade de Medicina que disponibilizaram o seu tempo dando aulas de inglês para as crianças do $5^{\circ}$ ano das escolas públicas de Botucatu. Ademais, agrademos às diretoras e professoras das Escolas Pacheco e Angelino, que abraçaram nosso projeto, disponibilizando espaço em sua grade horária e permitindo que o projeto pudesse se concretizar.

\section{Referências}

BRASIL. MEC. Parâmetros Curriculares nacionais: língua estrangeira / ensino fundamental. Brasília: MEC/SEF, 1998.

BROWN, H. D. Teaching by principles: and interactive approach to language pedagogy. 2 ed. San Francisco: State University, 2001.

FINI, I. M. Proposta Curricular do Estado de São Paulo: inglês. Coord. Maria Inês Fini. - São Paulo: SEE, 2008.

OLIVEIRA, M. K. Vygotsky. Aprendizado e desenvolvimento: um processo sóciohistórico. São Paulo: Scipione, 1993.

OLIVEIRA, M. K. Teorias psicogenéticas em discussão. São Paulo: Summus, 1992.

SÃO PAULO. Proposta Curricular de Língua Estrangeira Moderna: inglês 1o grau. São Paulo, SE/Cenp, 1988.

\section{Como citar este artigo:}

ROCHA, Nildicéia Aparecida et al. Ensino de línguas estrangeiras e prática médica no Projeto Let's go: uma perspectiva humanizada. Revista Ibero-Americana de Estudos em Educação, Araraquara, v. 12. N. 2, p. 1104-1116, 2017. Disponível em: <http://dx.doi.org/10.21723/riaee.v12.n2.9413>. E-ISSN: 1982-5587.

Recebido em: 18/02/2017

Aprovação final em: 04/04/2017 